\section{Pengembangan Multimedia Interaktif Berbasis Midnjet Mindmanager pada Materi Plantae untuk Siswa Kelas X SMA}

\author{
Nur Ummu Pratiwi Arifuddin \\ Hilda Karim \\ Adnan
}

\begin{abstract}
Abstrak. Penelitian ini bertujuan untuk mengembangkan produk media pembelajaran berupa multimedia interaktif berbasis Mindjet MindManager yang menggabungkan beberapa media (yakni teks, gambar, video animasi dan kuis interaktif) untuk mata pelajaran biologi materi plantae atau dunia tumbuhan. Penelitian ini menggunakan metode Research and Development $(\mathrm{R}$ \& D) dengan menggunakan model pengembangan ADDIE, yaitu analisis (analyze), desain (design), pengembangan (development), implementasi (implementation), dan evaluasi (evaluation). Produk multimedia interaktif berbasis mindjet mindmanager yang dikembangkan menitikberatkan pada proses pembelajaran yang variatif dan keaktifan peserta didik dalam pembelajaran. Pengembangan ini bertujuan menghasilkan produk multimedia interaktif yang bersifat valid dan praktis. Alat pengumpulan data yang digunakan berupa instrumen penilaian kevalidan dan kepraktisan. Hasil penilaian dari validator ahli menunjukkan bahwa produk yang dikembangkan layak untuk digunakan dan memperoleh nilai validitas 4,3 dengan presentase nilai $85 \%$ yang memenuhi standar kevalidan dan dapat dimanfaatkan sebagai media pembelajaran. Guru dan peserta didik juga menunjukkan respon positif terhadap multimedia interaktif. Kepraktisan media diperoleh respon guru dengan nilai $94,2 \%$ dan respon peserta didik dengan nilai $87,9 \%$ (sangat praktis). Berdasarkan hasil penelitian dapat disimpulkan bahwa media pembelajaran multimedia interaktif yang dikembangkan bersifat valid dan praktis, serta layak untuk diterapkan dalam sistem pembelajaran.

Kata kunci: multimedia interaktif, mindjet mindmanager, ADDIE, valid, praktis
\end{abstract}

\section{Pendahuluan}

Perkembangan ilmu pendidikan harus mengikuti perkembangan zaman. Seperti sekarang ini, teknologi memiliki peranan yang sangat penting untuk mendorong peningkatan mutu pendidikan. Hal ini dibuktikan dengan adanya sejumlah penelitian yang menunjukkan bahwa penggunaan Teknologi Informasi dan Komunikasi (TIK) sangat bermanfaat dan memberikan kontribusi yang signifikan bagi pengembangan pendidikan, (Noni, 2010). Menurut Mills (2006) dalam (Adnan, 2015), Penggunaan TIK membantu perkembangan pembelajaran dan memberi kesempatan kepada peserta didik dalam bentuk pencarian pemecahan masalah dan meningkatkan proses penciptaan ide, meningkatkan pemahaman peserta didik dengan materi pelajaran, meningkatkan motivasi guru dan peserta didik untuk helaiar dan mengaiar. dan meningkatkan

\section{Biology Teaching and Learning}

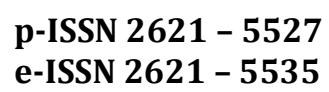

Abstract. This study aims to develop learning media products in the form of interactive multimedia based on Mindjet MindManager which combines several media (text, images, animated videos and interactive quizzes) for biology of plantae material or plant world. This study uses the Research and Development $(R \& D)$ method using the ADDIE development model, namely analysis (analyze), design (design), development (implementation), implementation (implementation), and evaluation (evaluation). Mind managerbased Mindjet-based interactive multimedia products are focused on the varied learning process and the activity of students in learning. This development aims to produce interactive multimedia products that are valid and practical. The data collection tool used is in the form of validity assessment and practicality instruments. The assessment results from expert validators show that the products developed are feasible to use and obtain a validity value of 4.3 with a percentage value of $85 \%$ that meets the validity standard and can be used as a learning medium. Teachers and students also show a positive response to interactive multimedia. The practicality of the media obtained teacher responses with a value of $94.2 \%$ and responses of students with a value of $87.9 \%$ (very practical). Based on the results of the study it can be concluded that the interactive multimedia

learning media developed are valid and practical, and feasible to be applied in the learning system.

Keywords: interactive multimedia, mindjet mindmanager, ADDIE, valid, practical

Nur Ummu Pratiwi Arifuddin Universitas Negeri Makassar Indonesia

Hilda Karim

Universitas Negeri Makassar Indonesia

Adnan

Universitas Negeri Makassar Indonesia 
Penggunaan TIK dengan tepat dapat berpengaruh secara positif terhadap aspek-aspek kehidupan sekolah, seperti pelaksanaan pembelajaran, mutu pembelajaran, dan kesempatan pengembangan guru. Hal ini menunjukkan bahwa teknologi dalam pendidikan sangat penting untuk meningkatkan hasil belajar siswa, (Adnan, Bundu P, \& Nurdin A, 2014).

Media pembelajaran merupakan alat bantu yang digunakan oleh tenaga pendidik dalam menyampaikan informasi yang diperlukan untuk meningkatkan pengetahuan peserta didik selama proses pembelajaran. Indriana (2011) berpendapat bahwa media yang tepat digunakan dalam proses pembelajaran untuk meningkatkan hasil belajar peserta didik dan harus disesuaikan dengan tipe belajar siswa yang beragam yakni visual, auditif, dan kinestetik. Sehingga, dibutuhkan media pembelajaran yang tepat dalam menangani hal tersebut.

Terdapat beberapa macam bentuk media yang biasa digunakan dalam proses pembelajaran. Anderson (1997) dalam (Riyana \& Deni Darmawan Asra, 2007) mengelompokkan media kedalam beberapa kelompok yakni media visual, audio, audio visual, multimedia dan media realita. Indriana (2011) mengatakan bahwa salah satu jenis media yang dapat mengatasi keberagaman gaya belajar siswa adalah penggunaan multimedia. Multimedia adalah media presentasi dengan menggunakan teks, audio dan visual sekaligus. Hal ini diartikan sebagai kombinasi atau gabungan dari beberapa media yakni memiliki unsur teks, grafik, audio dan animasi yang dapat digunakan untuk menyajikan sesuatu sehingga dipandang tepat dalam mengatasi keberagaman gaya belajar siswa.

Hasil observasi yang telah dilaksanakan di kelas X Mia 1 SMAN 10 Gowa ditemukan beberapa hambatan selama proses belajar mengajar yakni belum adanya pengembangan media pembelajaran yang menarik dan variatif terutama untuk mata pelajaran biologi. Peserta didik masih terlihat pasif dalam pembelajaran, hal ini disebabkan sumber pembelajaran yang masih berpusat pada guru (teacher center). Media pembelajaran yang digunakan guru masih monoton, sehingga menyebabkan pembelajaran di kelas kurang optimal. Pembelajaran hanya cenderung menggunakan buku teks dan kadang menggunakan Power Point. Buku teks yang tebal dan power point yang monoton serta kurang menarik, membuat siswa kadang mengalami kesulitan dalam mempelajari mata pelajaran biologi. Salah satu jenis software multimedia yang dapat digunakan dalam pembelajaran adalah Mindjet MindManager yang didalamnya dapat diintegrasikan teks, gambar, video dan quiz interaktif. Komponen tersebut dapat mendukung proses pembelajaran yang variatif dan membantu guru dalam menyampaikan ide-ide pembelajarannya.

\section{Metode Penelitian}

Jenis penelitian yang digunakan adalah Penelitian Pengembangan (Research and Development) yakni pengembangan multimedia interaktif berbasis mindjet mindmanager pada materi plantae untuk siswa kelas X SMA dengan menggunakan model ADDIE yaitu analyse (analisis), design (desain), development (perancangan), implementation (implementasi), evaluation (evaluasi). Penelitian ini dilaksanakan pada bulan agustus 2018 hingga november 2018. Tahap analisis di lakukan di SMAN 10 Gowa. Produk yang dikembangkan dinilai oleh dua validator ahli untuk menguji validatas produk. Untuk menguji kepraktisan dilakukan pada tahap implementasi dengan melihat penilaian praktisi dalam hal ini guru dan peserta didik sebagai responden.

\section{Hasil Penelitian}

Penelitian pengembangan yang telah dilakukan merupakan penelitian pengembangan yang menghasilkan produk berupa multimedia interaktif berbasis Mindjet MindManager materi plantae. Adapun hasil analisis uji kevalidan dan kepraktisan produk sebagai berikut. 
Pengembangan Multimedia Interaktif Berbasis Midnjet Mindmanager p-ISSN 2621-5527

Materi Plantae untuk Siswa Kelas X SMA

(hlm. 27-33)

\section{Uji Kevalidan}

Validasi multimedia interaktif dilakukan hingga diperoleh multimedia yang valid. Adapun hasil penilaian kedua validator dari keenam aspek penilaian diuraikan dalam tabel berikut.

\section{Tabel 1. Rata-Rata Penilaian Validator Terhadap Multimedia Interaktif Berbasis Mindjet} Mindmanager

\begin{tabular}{|c|c|c|c|}
\hline No. & Aspek yang dinilai & $\begin{array}{c}\text { Skor rata- } \\
\text { rata }\end{array}$ & Keterangan \\
\hline 1 & Rekayasa Perangkat Lunak & 4,2 & Valid \\
\hline 2 & Kelayakan Penyajian & 4,4 & Valid \\
\hline 3 & Desain Pembelajaran & 4,1 & Valid \\
\hline 4 & Tampilan Visual & 4,2 & Valid \\
\hline 5 & Bahasa & 4,7 & Sangat valid \\
\hline 6 & Efek bagi Stratergi Pembelajaran & 4,3 & Valid \\
\hline \multicolumn{2}{|c|}{ Rata-rata } & $\mathbf{4 , 3}$ & Valid \\
\hline & Persentase (\%) & $\mathbf{8 5}$ & Valid \\
\hline
\end{tabular}

Hasil penilaian validasi tersebut kemudian dianalisis secara deskriptif, sehingga diperoleh rata-rata nilai validasi $\left(\mathrm{V}_{\mathrm{a}}\right)$ yaitu 4,3 . Dengan presentase $85 \%$ yang tergolong dalam persentase kriteria kevalidan produk (75-85) yaitu valid. Adapun dari keenam aspek yang dinilai, aspek bahasa merupakan aspek dengan skor tertinggi yaitu 4,7 yang tergolong kriteria sangat valid. Dan kelima aspek lainnya tergolong kriteria valid.

\section{Uji Kepraktisan}

Uji kepraktisan dilakukan oleh guru melalui angket respon guru dan peserta didik melalui angket respon peserta didik. Adapun hasil penilaian diuraikan dalam tabel 2 dan 3.

\section{Tabel 2. Penilaian Guru Terhadap Multimedia Interaktif Berbasis Mindjet Mindmanager}

\begin{tabular}{|c|c|c|c|c|}
\hline No. & Aspek yang Dinilai & $\begin{array}{c}\text { Skor Aspek } \\
(\mathbf{X} \boldsymbol{i})\end{array}$ & $\begin{array}{c}\text { Skor Maksi- } \\
\text { mum } \\
(\boldsymbol{X} \boldsymbol{j})\end{array}$ & $\begin{array}{c}\text { Presentase } \\
\text { Aspek } \\
(\mathbf{\%})\end{array}$ \\
\hline 1. & Rekayasa perangkat lunak & 30 & 30 & 100 \\
\hline 2. & Relevansi materi & 74 & 80 & 87,5 \\
\hline 3. & Tampilan visual & 28 & 30 & 93,3 \\
\hline 4. & Konstruksi pengetahuan & 47 & 50 & 94 \\
\hline \multicolumn{7}{|l}{} \\
\hline
\end{tabular}

Tabel 3. Penilaian Peserta Didik Terhadap Multimedia Interaktif Berbasis Mindjet Mindmanager

\begin{tabular}{|c|c|c|c|c|}
\hline No. & Aspek yang Dinilai & $\begin{array}{c}\text { Skor Aspek } \\
(\mathbf{X} \boldsymbol{i})\end{array}$ & $\begin{array}{c}\text { Skor Maksimum } \\
(\boldsymbol{X} \boldsymbol{j})\end{array}$ & $\begin{array}{c}\text { Presentase Aspek } \\
(\mathbf{\%})\end{array}$ \\
\hline 1. & Ketertarikan & 1148 & 1305 & 87,96 \\
\hline 2. & Materi & 755 & 870 & 86,78 \\
\hline 3. & Bahasa & 266 & 290 & 91,72 \\
\hline \multicolumn{2}{|l}{ Persentase Respon Peserta didik $(\boldsymbol{P})$} & $\mathbf{8 7 , 9} \%$ \\
\hline
\end{tabular}

Hasil uji kepraktisan multimedia interaktif berdasarkan respon guru menunjukan persentase $94,2 \%$ dan respon peserta dididk menunjukkan persentase $87,9 \%$. Jika ditinjau dari pengkategorian kepraktisan produk, persentase tersebut berada pada tingkatan 80-100 yang menunjukan bahwa multimedia interaktif berbasis Mindjet Mindmanager yang dikembangkan termasuk ke dalam kategori sangat praktis dan dapat digunakan dalam pembelajaran. 


\section{Pembahasan}

Pengembangan multimedia interaktif berbasis Mindjet MindManager dilakukan dengan uji kevalidan dan kepraktisan dari mind map yang dikembangkan sebagai produk yang bersifat valid dan praktis. Pengembangan multimedia interaktif dilakukan dengan melakukan studi literatur dari berbagai sumber. Selain itu penyusunannya dilakukan dengan berpedoman pada silabus kurikulum 2013 edisi revisi yang berlaku, sehingga pencapaian dasar yang diharapkan ada pada peserta didik disesuaikan dengan materi.

Pengembangan produk multimedia interaktif berbasis Mindjet MindManager ini mengacu pada model ADDIE, oleh karenanya proses pengembangannya meliputi tahapan analisis (analyze), desain (design), pengembangan (development), implementasi (implementation) dan evaluasi (evaluation). Pengembangan multimedia interaktif juga mengacu pada hasil analisis kebutuhan peserta didik yang telah dilakukan yakni dengan menyebar angket ke 30 peserta didik sebagai sampel penelitian. Hasil analisis awal yang telah dilakukan ditemukan bahwa 93\% peserta didik membutuhkan sumber belajar baru yang lebih inovatif khususnya pada materi yang sifatnya sulit divisualisasikan jika hanya menggunakan buku teks dan power point yang monoton.

Materi yang dipilih pada penelitian pengembangan ini yakni materi plantae atau dunia tumbuhan. Pemilihan materi tersebut berdasarkan hasil analisis wawancara dengan guru biologi kelas X bahwa salah satu materi yang memerlukan proses pencarian diinternet sebagai tambahan referensi adalah materi dunia tumbuhan khususnya terkait kenaekaragamannya, disisi lain, jika guru ingin mengajak peserta didik untuk belajar langsung di lingkungan sekitar, maka membutuhkan pengawasan yang cukup besar dan juga waktu yang lebih banyak. Hal tersebut membuat peserta didik cenderung menjadi pasif dalam pembelajaran di kelas.

Materi pembelajaran menempati posisi yang sangat penting dari keseluruhan kurikulum, yang harus dipersiapkan agar pelaksanaan pembelajaran dapat mencapai sasaran. Sasaran tersebut harus sesuai dengan standar kompetensi dan kompetensi dasar yang harus dicapai oleh peserta didik. Artinya, materi yang ditentukan untuk kegiatan pembelajaran hendaknya materi yang benar-benar menunjang tercapainya standar kompetensi dan kompetensi dasar, serta tercapainya indikator (Depdiknas, 2008).

Pengembangan sumber belajar di Indonesia kurang dikembangkan dan didayagunakan dengan perkembangan teknologi yang memengaruhi proses belajar dan membelajarkan. Oleh karena itu pengembangan sumber belajar berbasis teknologi informasi perlu dikembangkan karena beberapa hal diantaranya yaitu (1) alokasi waktu pembelajaran di sekolah terbatas sehingga tidak mencapai kompetensi yang diharapkan, (2) peserta didik perlu menemukan informasi berupa pengetahuan yang baru secara mandiri, (3) peserta didik memiliki gaya belajar yang berbeda sehingga perlu diwadahi sumber belajar yang memenuhi beberapa gaya belajar dengan memanfaatkan beragam media (Thoriqi, 2016).

Peneliti mengembangkan produk multimedia interaktif berbasis Mindjet MindManager dengan tujuan agar memudahkan peserta didik dalam mencerna dan memahami suatu pembelajaran serta lebih memotivasi peserta didik dalam belajar, terlebih lagi produk multimedia interaktif yang dikembangkan ini menggabungkan beberapa media berupa teks, gambar, video animasi dan kuis interaktif dalam satu kesatuan berupa mind map. Hal ini menunjukkan bahwa keberagaman gaya belajar peserta didik dengan tipe belajar visual, audio, kinestetik, audio-visual dan lainnya dapat teratasi.

Dalam usaha memanfaatkan media pembelajaran, Edgar Dale mengadakan klasifikasi pengalaman berlapis menurut tingkat dari yang paling konkrit ke yang paling abstrak, sehingga dapat digunakan untuk menentukan tingkat efektivitas suau media pembelajaran. Klasifikasi tersebut dikenal dengan nama "Kerucut pengalaman Edgar Dale", dimana dengan menggunakan media berupa video pembelajaran, peserta didik akan lebih faham dengan konten materi yang diajarkan nantinya, dan belajar dapat menjadi lebih variatif, dibandingkan hanya berupa teks 
maupun gambar biasa (Chandra, 2011). Penelitian menunjukkan bahwa penggunaan media pembelajaran yang dikembangkan dengan menggabungkan beberapa media pada mata pelajaran biologi dapat meningkatkan motivasi dan hasil belajar peserta didik, (Triyanti, 2015).

Setelah melakukan tahap analisis awal, kemudian sampailah pada tahap desain. Tahap desain fokus kepada rancangan intrumen dan produk yang akan dihasilkan. Kemudian setelah melakukan perancangan, hasil yang diperoleh akan dikembangkan sehingga menghasilkan suatu produk multimedia interaktif berbasis Mindjet MindManager serta instrumen yang menjadi landasan dalam penilaian baik dari uji kevalidan maupun uji kepraktisan pada tahap implementasi.

Pada tahap pengembangan, produk yang dihasilkan dikembangkan berdasarkan saran dari pembimbing dan validator ahli. Terdapat beberapa aspek yang dikembangkan yakni dalam penyusunan teks, pemilihan gambar, maupun pemilihan indikator yang sesuai dengan produk yang ingin dikembangkan nantinya. Hasil yang diperoleh dalam tahap ini adalah produk multimedia interaktif berbasis Mindjet MindManager materi plantae atau dunia tumbuhan, dan instrumen kevalidan yang bersifat valid.

Validitas produk multimedia interaktif berbasis Mindjet MindManager diuji pada tahap pengembangan berlangsung. Menurut Arikunto (2010), validitas adalah tingkat kevalidan suatu instrumen. Suatu instrumen yang valid atau sahih mempunyai validitas tinggi. Sebaliknya, instrumen yang kurang valid berarti memiliki validitas rendah. Uji kevalidan multimedia interaktif ini dilakukan untuk melihat kekurangan multimedia interaktif berbasis Mindjet MindManager, baik dari segi konten maupun tampilan produk. Instrumen yang digunakan dalam pengembangan multimedia interaktif ini terdiri atas angket penilaian produk multimedia interaktif, instrumen penilaian angket respon guru dan angket respon peserta didik.

Validasi produk multimedia interaktif berbasis Mindjet MindManager dilakukan oleh 2 orang validator ahli dengan cara melihat dan menilai produk multimedia interaktif berbasis Mindjet MindManager yang dibuat, kemudian memberikan nilai pada instrumen lembar validasi. Kevalidan produk multimedia interaktif merupakan syarat yang harus dipenuhi sebelum produk multimedia interaktif berbasis Mindjet MindManager diimplementasikan kepada subjek penelitian. Kriteria penilaian yang digunakan untuk menentukan kevalidan multimedia interaktif berbasis Mindjet MindManager terdiri dari 6 aspek penilaian, yakni aspek rekayasa perangkat lunak, kelayakan penyajian, desain pembelajaran, tampilan visual, bahasa dan efek bagi strategi pembelajaran.

Berdasarkan hasil analisis data kevalidan multimedia interaktif berbasis Mindjet MindManager diperoleh nilai kevalidan dari validator untuk setiap aspek penilaian yaitu rekayasa perangkat lunak adalah 4,2; kelayakan penyajian adalah 4,4; desain pembelajaran adalah 4,1; tampilan visual adalah 4,2; bahasa adalah 4,7 dan efek bagi strategi pembelajaran adalah 4,3. Skor rata-rata keseluruhan untuk penilaian modul pembelajaran dari validator ahli adalah 4,3 dengan presentase $85 \%$ yang berarti valid. Kevalidan multimedia interaktif berbasis Mindjet MindManager berdasarkan aspek penilaian produk multimedia interaktif unggul dalam aspek bahasa berdasarkan hasil validasi dari para validator, dimana validator memberikan penilaian dalam kategori sangat valid, yakni 5.

Kevalidan multimedia interaktif juga didukung oleh kevalidan instrumen penilaian angket kepraktisan. Instrumen penilaian angket kepraktisan berupa angket respon guru dan angket peserta didik dinilai dari tiga aspek yaitu petunjuk, cakupan komponen angket, dan bahasa. Penilaian validator terhadap instrumen penilaian angket respon guru yakni pada aspek petunjuk yaitu 4,5 yang berarti sangat valid, aspek cakupan komponen angket yaitu 4,1 yang berarti valid, dan aspek bahasa yaitu 5 yang berarti sangat valid. Rata-rata dari penilaian instrumen angket respon guru yaitu 4,53 dan masuk ke dalam kategori sangat valid. Adapun penilaian validator terhadap instrumen penilaian angket respon peserta didik yakni pada aspek aspek petunjuk yaitu 4,3 yang berarti valid, aspek cakupan komponen angket yaitu 4,2 yang 
berarti valid, dan aspek bahasa yaitu 4,5 yang berarti sangat valid. Rata-rata dari penilaian instrumen angket respon guru yaitu 4,32 dan masuk ke dalam kategori valid.

Produk multimedia interaktif berbasis Mindjet MindManager yang telah dinyatakan valid dapat diimplementasikan kepada subjek penelitian untuk mengetahui kepraktisan terhadap produk multimedia interaktif dan dievaluasi. Tahap implementasi produk dilakukan di SMAN 10 Gowa dengan merujuk pada penilaian praktisi dalam hal ini 2 orang guru biologi, dan melihat respon 29 orang peserta didik kelas X MIA 1 SMAN 10 Gowa, untuk melihat apakah produk yang dihasilkan bersifat praktis digunakan dalam proses pembelajaran. Dari hasil penilaian oleh praktisi dengan pemberian angket untuk menilai produk multimedia interaktif berbasis Mindjet MindManager diperoleh nilai 94,21\%. Adapun hasil penilaian oleh responden dalam hal ini peserta didik kelas X Mia 1 diperoleh nilai 87,96\%. Hasil yang diperoleh dari praktisi dan responden mendapatkan presentase nilai kepraktisan dalam kategori (81-100) yaitu sangat praktis digunakan dalam proses pembelajaran.

Tahap terakhir yaitu evalusi, hasil yang diperoleh setelah tahap pengembangan dan implementasi terhadap multimedia interaktif berbasis Mindjet MindManager yang dikembangkan dianggap berhasil. Kevalidan dan kepraktisan dapat dijadikan data untuk menyatakan bahwa hasil evaluasi dari pengembangan produk multimedia interaktif berupa mind map pada Mindjet MindManager tersebut bersifat valid dan praktis, serta dapat digunakan dalam dunia pendidikan.

Kendala dari penelitian yang dilaksanakan berupa kurangnya sumber dalam negeri mengenai video animasi pembelajaran yang berkualitas terkhusus materi plantae, sehingga perlunya membuat video sendiri dan bekerjasama dengan powtoon.com dan channel dalam youtube untuk menghasilkan video animasi pembelajaran yang dinilai baik untuk digunakan. Sumber informasi mengenai materi plantae yang dapat disesuiakan dengan tingkat perkembangan peserta didik Sekolah Menengah Atas juga dinilai kurang, sehingga cukup sulit dalam menyesuaikan konten materi dan indikator yang dapat dicapai selama proses pembelajaran. Dalam hal ini, perlu kaji literatur yang mendalam terkait materi dari berbagai sumber yang ada sehingga dihasilkan produk yang valid dan praktis.

\section{Kesimpulan}

Multimedia interaktif berbasis mindjet mindmanager berupa mind map pada materi plantae yang dikembangkan bersifat valid, dimana kevalidan multimedia interaktif dengan nilai validitas $85 \%$ yang memenuhi standar kevalidan yaitu pada 75-85 atau valid. Angket respon guru dengan nilai 4,5 yang masuk kedalam kategori kevalidan yaitu $4,5 \leq X \leq 5$ atau sangat valid. Dan angket respon peserta didik dengan nilai validitas 4,3 yang memenuhi standar kevalidan yaitu pada kategori 3,5 $\leq \mathrm{V}_{\mathrm{a}}<4,5$ atau valid.

Multimedia interaktif berbasis mindjet mindmanager berupa mind map pada materi plantae yang dikembangkan bersifat praktis.

\section{Referensi}

Adnan. (2015). Model Pembelajaran Biologi Konstruktivistik Berbasis TIK (MPBK Berbasis TIK) untuk Siswa Smp. Journal of EST, 1 (1).

Adnan, Bundu P. \& Nurdin A. (2014). The Improving of Junior High School Student in Learning Motivation Through Implementation Constructivistic Biology Learning Model Based On Information and Communication, 5 (2).

Arikunto, S. (2010). Prosedur Penelitian Suatu Pendekatan Praktik. Jakarta. PT. Rineka Cipta. 
Chandra, E. (2011). Efektivitas Media Pembelajaran dalam Pembelajaran Biologi (Meta Analisis terhadap Penelitian Eksperimen dalam Pembelajaran Biologi). Holistik, 12 (1).

Indriana, D. (2011). Ragam Alat Bantu Media Pengajaran. Yogykarta. Diva Press.

Noni, N. (2010). Teknologi Informasi dan Komunikasi dalam Pendidikan. Makassar. Badan Penerbit Universitas Negeri Makassar.

Riyana, C. \& Deni D. A. (2007). Komputer dan Media Pembelajaran di SD. Jakarta. Direktorat Jenderal Pendidikan Nasional.

Thoriqi, M. W. (2016). Pengembangan Multimedia Pembelajaran Interaktif berbasis Adobe Flash sebagai Media pembelajaran Akuntansi pada Kompetensi Menyiapkan Konsep Dasar Pajak untuk Meningkatkan Motivasi Belajar Siswa Kelas XI Akuntansi di SMK Negeri 1 Tempel. Skripsi. Yogyakarta. Universitas Negeri Yogyakarta.

Triyanti, M. (2015). Pengembangan Multimedia Interaktif pada Materi Sistem Saraf untuk Meningkatkan Motivasi dan Hasil Belajar Siswa SMA Kelas XI. Jurnal BIOEDUKATIKA, 3 (2).

\begin{tabular}{|l|l|}
\hline $\begin{array}{l}\text { Nur Ummu Pratiwi } \\
\text { Arifuddin }\end{array}$ & $\begin{array}{l}\text { Jurusan Biologi, Fakultas Matematika dan Ilmu Pengetahuan Alam, } \\
\text { Universitas Negeri Makassar. } \\
\text { Email: } \underline{\text { ummuprtiwi@gmail.com }}\end{array}$ \\
\hline Hilda Karim & $\begin{array}{l}\text { Dr. M.S, Dosen Jurusan Biologi, Fakultas Matematika dan Ilmu } \\
\text { Pengetahuan Alam, Universitas Negeri Makassar. } \\
\text { Email: hildakarim@yahoo.com }\end{array}$ \\
\hline Adnan & $\begin{array}{l}\text { Dr. M.S, Dosen Jurusan Biologi, Fakultas Matematika dan Ilmu } \\
\text { Pengetahuan Alam, Universitas Negeri Makassar. } \\
\text { Email: adnan unm@yahoo.co.id }\end{array}$ \\
\hline
\end{tabular}

